THE SPOCKIAN MOTHER

\title{
The Spockian Mother: Images of the “Good" Mother in Dr. Spock's The Common Sense Book of Baby and Child Care, 1946-1992
}

Catherine A. Dobris, Kim White-Mills, Rachel D. Davidson, \& Toula V. Wellbrook

\begin{abstract}
Dr. Spock's, The Common Sense Book of Baby and Child Care, one of the best-selling self-help texts of all-time, "second only to the Bible in popularity" (Meakin \& Tattersall, 2004) was one of the most influential childcare books in American culture. The author has been both heralded and disparaged as instrumental in the shaping of untold generations. In the present study, we address the rhetorical construction of the Spockian Mother as she is developed during Spock's tenure from 1946-1992. We employ a feminist rhetorical perspective to examine the progression of Spock's texts in order to understand how patriarchal images of motherhood are constructed and maintained through Spock's lifetime and the first 46 years of its publication. We argue that Spock both reinforced and challenged the institution of motherhood; he challenged institutionalized motherhood by encouraging mothers to "trust themselves" while simultaneously conforming to a patriarchal model of motherhood which is at odds with empowered mothering.
\end{abstract}

Keywords: Childrearing, Feminist Criticism, Mothering, Motherhood, Rhetorical Construction 


\section{THE SPOCKIAN MOTHER}

The Spockian Mother: Images of the "Good” Mother in Dr. Spock's The Common Sense Book of Baby and Child Care, 1946-1992

\section{Introduction}

For more than half a century, the most recognizable name in the realm of childcare texts has been Dr. Spock. As author of the 1946, The Common Sense Book of Baby and Child Care, one of the best-selling books of all-time (Hidalgo, 2011, para. 1), "second only to the Bible in popularity" (Meakin \& Tattersall, 2004) and one of the most influential childcare books in American culture, Spock assisted in the shaping of untold generations ${ }^{\mathrm{i}}$. In Thomas Maier's (1998) biography, Dr. Spock: An American Life, he writes:

In terms of sheer influence, what president, general, or tycoon could claim to have affected the fundamental way we bring up our children and carry on our species? In historical volumes found in every library, Spock's name is on the list of those who have changed our world. (p. xii)

The 1946 edition of The Common Sense Book of Baby and Child Care was a major best seller for over a decade (Bloom, 1972) until the second edition appeared in 1957. A third update was published in 1968, providing modern perspectives on some outmoded ideas from the first two editions. In 1976, in the fourth edition, Spock incorporated ideas from the Women's Movement in an attempt to alter the vision of motherhood pervading the text, to embody the rapid changes that were occurring in the evolution of women's roles in society. Finally, in the 1985 and 1992 versions, pediatrician Michael Rothenberg joined Spock as co-author, to expand and modernize the legendary text. For more than four decades, Spock's singular vision of motherhood as the ultimate achievement for all women remained an idealized image for millions of American 


\section{THE SPOCKIAN MOTHER}

families, continuing with further editions even after Spock's death. Influencing generations of children who have been raised "by the book," Spock has also helped contour the institution of American motherhood.

Scholars have studied motherhood from a variety of perspectives, including advancing "mothering" as an experience that is different from "motherhood as institution" (Dubriwny \& Ramadurai, 2013; Gilbert, 2008; Harris, 2002). For example, Rich (1986) advances a dual conceptualization of motherhood as one which can be an empowering personal experience but is likewise an institution that reinforces patriarchal expectations about mothers. Rich (1986) avers there are "two meanings of motherhood, one superimposed on the other: the potential relationship of any woman to her powers of reproduction and to children; and the institution, which aims at ensuring that that potential - and all women — shall remain under male control" (p. 13). Building on Rich's distinction between these two meanings of motherhood, other scholars explore "the oppressive and the empowering aspects of maternity, and the complex relationship between the two" (O’Reilly, 2006, p. 323). For example, O’Brien Hallstein (2006) distinguishes between institutionalized motherhood and empowered mothering, arguing that it is incumbent on feminists to investigate "both institutionalized motherhood and a relational empowered mothering, which both continue to be part and parcel of contemporary maternity for all feminist mothers" (pp. 105-6). Hays (1996) reveals dominant ideologies of motherhood that reinforce the dichotomous "good" and "bad" mother, and Foss and Domenici (2001) and Buchanan (2013) theorize regarding the rhetorical nature of motherhood. Specifically, Buchanan (2013) asserts that "[d]iscourses about mothers, mothering, and motherhood permeate U.S. political culture and are employed by both women and men in order to advance themselves and their agendas within the public realm" (p. xvii). The current essay seeks to contribute to this academic discussion on 


\section{THE SPOCKIAN MOTHER}

motherhood, by illuminating Spock's construction of "mother," in his influential text. We argue that Spock both challenged and reinforced the institution of motherhood by encouraging mothers to "trust themselves," contrary to institutionalized norms, while simultaneously adopting a patriarchal model of motherhood which is at odds with what some scholars have termed “empowered mothering” (Rich, 1986). We address the rhetorical construction of the Spockian Mother as presented in the text, The Common Sense Book of Baby and Child Care, developed from 1946-1992, during Spock's lifetime. ${ }^{i i}$ The Spockian Mother evolves throughout the six editions of the text; she is constrained by the hegemonic principles that more obviously circumscribe her efforts in the 1940s and is ultimately shaped within a patriarchal structure that empowers her to "have it all," and therefore also, "do it all," by the 1990s.

Employing a feminist rhetorical perspective, we examine the texts published from 1946 to 1992 to understand how patriarchal images of motherhood are both challenged and reinforced. We examine two key issues: 1) how the Spockian Mother was rhetorically constructed and promulgated in the original 1946 text, and 2) the extent to which that construction was altered in the five subsequent revisions through the 1992 edition of the text. By addressing these concerns, we seek to understand how Spock's books work rhetorically in shaping the Spockian Mother as an exemplar for mothers in contemporary culture.

\section{An Ideological Approach to the Construction of Motherhood}

In her seminal text, Of Woman Born, Rich (1986) offers an interpretation of motherhood as both rooted in women's private experiences as mother and daughter and as a social institution that shapes the real lives of mothers. Enoch (2012) reaffirms the gendered and patriarchal view of motherhood as a social institution in the United States in her treatise regarding WWII working mothers. Similarly, Hays (1996) describes a dominant, white, middle-class model of childrearing 


\section{THE SPOCKIAN MOTHER}

that prescribes a set of standards for mothers which will fortify their "good mother" statuses. Hays" "intensive mothering model" indicates that "good mothers" are child-centered, primary caregivers, consult expert guided opinions on childrearing, and see childrearing as "emotionally absorbing," "labor intensive," and "expensive" (p. 8). O’Brien Hallstein (2010) observes that "even though not all women practice intensive mothering...it is the proper ideology of contemporary mothering that all women are disciplined into and judged against, across race and class lines" (p. 63). The intensive mothering model, as a dominant ideology, is further examined in analysis of images of motherhood in media. For example, Douglas and Michaels' (2005) The Mommy Myth: The Idealization of Motherhood and How It Has Undermined All Women, explore how intensive mothering expectations are embedded in American mass media and shape ideals of motherhood. By examining these expectations regarding motherhood and childrearing as manifested in the texts, we suggest that the Spockian Mother both reinforces and challenges aspects of intensive mothering that empower mothers while concomitantly encouraging patriarchal enactments of motherhood that undermine personal agency. In this context, agency is considered the extent to which mothers' may define for themselves what is or is not "good" mothering in response to or in defiance of patriarchal conceptions of motherhood.

Ideological criticism, informed by a feminist approach, provides a framework to assess images of American motherhood in order to illuminate the text from a woman-centered standpoint. Sonja Foss (1996) suggests that "[t]hose who create culture and its various manifestations" generate symbols "from their own point of view, putting themselves at the center" (p. 167). It is therefore inevitable that "culture features men's perspectives and devalues and silences those of women" (pp. 166-167). To the extent that Spock articulated a powerful worldview emanating from the almost exclusively white, middle class, male bastion of the 


\section{THE SPOCKIAN MOTHER}

medical community, it is important to understand these images from a woman-centered perspective in order to deconstruct his projection of women's roles onto his vision of motherhood. Ideological criticism, informed by a feminist lens, allows us to explore these questions by beginning with Foss' (1996) approach to evaluation, examining the "construction of gender" in regard to the Spockian Mother, and exploring how this construction may "maintain" or "challenge and transform" patriarchal conceptions of women (pp. 169-170). Our approach is one where "the critic looks beyond the surface structure of an artifact to discover the beliefs, values, and assumptions it suggests" (Foss, 2009, p. 209). In what follows, we discuss the exigencies which prompted Spock's initial text and provide a brief historical overview of childcare theories leading up to the publication of his first book. Next, we examine the artifacts within the rhetorical universe of childcare literature. Finally, we provide analysis of the constructions of the Spockian Mother as she emerged through five decades of revision.

\section{Background}

Maxine Margolis (2000) offers valuable insight into the historical patriarchal hegemony throughout the history of childrearing texts and treatises, observing three important trends. First, early childrearing advice in the form of sermons during the colonial period did not assume that mothers were the primary childcare givers. Second, it was not until the late eighteenth century that rhetors begin to emphasize childrearing as a primary responsibility of the mother. Third, and most significantly from a rhetorical perspective, Margolis (2000) argues that even before the emergence of a cult of motherhood, women had little voice in shaping how and what should be the process of childrearing. Childcare manuals were originally written by men for men and, later, by men for women. Although women were historically responsible for most, if not all, childcare duties, women were systematically excluded from the discourse on the theory and practice of 


\section{THE SPOCKIAN MOTHER}

childrearing--their voices minimized, disparaged and often altogether absent. Certainly the dearth of reading instruction available to most women during this time, provided a rationale to direct texts to a more educated male population, but this was only a small part of the justification. Men were unequivocally seen as the proper authorities for overseeing childrearing. Even when women were the audience for some texts, they “were told to take careful notes on their children's development and behavior, to provide the raw data for the 'experts' who then devised the rules that mothers were to follow" (p. 27). Although during the late 1800s and early 1900s ideologies about the nature of children and childrearing began to shift, and literacy rates increased for women as education became more widely available, the voice of the patriarch still reigned as the preeminent voice in childcare literature.

In 1929, Spock was an unpaid medical intern at the Presbyterian Hospital affiliated with Columbia University, in New York City. His wife, Jane, worked part-time as a research assistant for Dr. George Draper of the Constitution Laboratory of Presbyterian Hospital. Draper, a friend of Spock's, was exploring a possible link between psychology and susceptibility to physical infirmities (Maier, 1998, p. 77). At the same time, the emerging study of psychoanalysis intrigued both Spocks, and subsequently, Dr. Spock began his own analysis of Freud's theories of emotional development and their possible application to pediatrics. Although Spock apparently had an ample supply of childcare advice for new mothers, derived from his own medical practice and experience, according to Maier (1977), he was troubled by his inability to satisfactorily explain the theories behind his promotion of one childrearing practice versus another. Spock alleged that the study of psychology and psychoanalysis provided a foundation for understanding motivations for human behavior and therefore supplied explanations for advocating particular codes of conduct. Spock had embarked upon identifying a connection 


\section{THE SPOCKIAN MOTHER}

between psychology and pediatrics and he pioneered a field that would incorporate both areas of study (Bloom, 1972). This connection formed the foundation of The Common Sense Book of Baby and Child Care.

Eventually, Spock was asked by an editor at Pocket Books to write a pamphlet with advice to mothers on parenting that would incorporate Freudian psychology without alarming the reading public through referencing the controversial psychiatrist (Maier, 1998). Biographical accounts suggest that Spock was selected by Pocket Books precisely because of the Freudian influences on his approach to pediatrics and his willingness to camouflage Freudian psychology in the text (Bloom, 1972; Kaye, 1993; Maier, 1998). Spock advocated that children were basically "good" and wanted to have their parents' approval. He also argued that "good" mothers did not need to be scientists to be good parents; they needed only to follow their own instincts and their doctor's advice (Kaye, 1993; Maier, 1998). Thus, Spock used his own perceptions of childhood and mothering, underpinned by emerging theories in the field of psychoanalysis, to ground his definition of "common sense" in childrearing. In every respect, his sources of authority were male or male-centered, thus replicating a patriarchal conception of motherhood.

According to Maier (1998), Spock was counseled that he did not have to write a "very good" book (p. 125) since the publishers hoped only to sell a modest 10,000 copies a year. His wife convinced him to take on the assignment regardless, and she acted as his researcher, typist, and editor. ${ }^{\text {ii }}$ The Common Sense Book of Baby and Child Care sold over 750,000 copies in the first year of circulation, far exceeding the expectations of the publisher (Maier, 1998). The paperback version was sold for a moderate cost of twenty-five cents purportedly to be widely accessible to American mothers, regardless of socio-economic circumstances. Freud's ideas remained controversial, but Spock's popularization of psychoanalytic theory as an unspoken 


\section{THE SPOCKIAN MOTHER}

backdrop in the self-help genre of childrearing was instrumental in establishing a Freudian paradigm in the American psyche, at least in regard to childrearing (Bloom, 1972; Maier, 1998). Overnight, Spock's book became indispensable for many middle-income families eager to have the most current information on childrearing.

Although affordable, one early critique of the book was that it contained elitist assumptions and catered to the middle and upper classes (Maier, 1998). According to Maier, despite receiving criticism for its elitist bias, however, the book elicited numerous letters thanking Spock for his practical advice and for instilling confidence in new mothers. Though his advice was couched as "commonsense," much of what he presented in his original text was not particularly common at the time; instead he promulgated beliefs derived from his personal experience as a pediatrician and on the popular views of colleagues in the medical profession, in such a way as to create the "common sense" he professed to represent. Even today, when parents suggest that childrearing is intuitive, it may be Spock's conception of "common sense," inculcated in our cultural beliefs about childrearing, which is unknowingly advanced.

Spock took issue with many prevailing medical perspectives of the day. For example, it was he who made recommendations about the advisability of delaying toilet training past the 3-4 month age range, suggested by some of his learned peers. Moreover, Spock challenged leading childrearing authorities, such as Dr. Luther Emmett Holt (1894), who admonished in the 1890s that, given the possibility of transmitting disease, "[I]nfants should be kissed, if at all, upon the cheek or forehead ... but the less of this the better" (p. 61) and echoed thirty years later, by psychologists such as John B. Watson (1928) who commanded mothers to "Never hug and kiss them, never let them sit in your lap ...” (pp. 81-82). In contrast, Spock advised a modern generation of post WWII mothers that picking up a crying baby could be undertaken without 


\section{THE SPOCKIAN MOTHER}

"spoiling" the child, and further, that hugging one's toddler was preferable to the experts' advice of minimizing physical contact. Contrary to the opinions of his predecessors, Spock advised mothers that it was appropriate to show affection to babies and children, and advised against corporal punishment as a regular form of discipline. He counseled that children might be toilet trained successfully up until eighteen months and deemed thumb sucking a problem unworthy of tormenting the offender, unlike many of his contemporaries. He also advocated "natural" breastfeeding over the use of the more popular "scientific" recommendations to use formula, and believed that left to their own devices, without imposing a rigid eating schedule, children would eat balanced and nutritional meals. For many mothers, reared under the influences of Holt and Watson, Spock's evocation to follow their intuition, must have been a relief in contrast to mandates to resist maternal instincts. Spock's perspective challenged some of the givens of patriarchal conceptions of motherhood, offering women the opportunity to enact agency through defining "good" mothering on their own terms.

But, whether Spock merely popularized the emerging ideas of his 1940s colleagues and thus reflected the changing American landscape, or whether he challenged and transformed the culture to one of his own devising, has been debated by biographers such as Bloom (1972) and Maier (1998). Without question, The Common Sense Book of Baby and Child Care stands as a major rhetorical artifact in the annals of childrearing. Spock's initial presentation of childrearing theories and subsequent advice was said to be so influential that presidents' wives, such as Eisenhower and Kennedy, publicly endorsed the book that ostensibly shaped their own childrearing techniques.

Although the success of the initial publication surpassed all expectations, colleagues in the medical community were highly critical of Spock's work (see discussions of early critiques 


\section{THE SPOCKIAN MOTHER}

in Maier, 1998; Margolis, 2000; Meakin \& Tattersall, 2004). Many felt that he surrendered his medical and scholarly ethics by publishing a nonacademic book in the still emerging self-help genre. Other scholars argued that his book lacked scientific backing. Over the next five decades Spock's book continued to sell worldwide, but his advice was interpreted in such a multiplicity of ways that he spent much of his career alternately defending and reconsidering his positions.

\section{Constructing the Spockian Mother}

Beginning our analysis with the original 1946 volume, we examine the six editions over half a century of publication, and investigate how the Spockian Mother emerged in each edition. We employ an ideological critique that looks for "the assumptions or premises behind the artifact that constitutes its ideology" (Foss, 2009, p. 214). In order to identify the assumptions, we look for elements that are present, or "basic observable features of the artifact" (Foss, 2009, p. 214), that reveal what is suggested in the artifact, including "ideas, references, themes, allusions or concepts that are suggested by the presented elements" (Foss, 2009, p. 216). Five themes emerged, representing the specter of the Spockian Mother: 1) "good" childrearing practices, 2) appropriate sources of authority, 3) how mother feels, 4) role of father in relation to parenting, and 5) roles of mother outside of parenting. The first three themes emerge with regularity in the first and subsequent versions of the text, while the latter two themes (i.e., role of the father in relation to parenting and roles of mother outside of parenting) become redefined in later versions of the text. For instance, in the first three editions, the role of father in relation to parenting is one where the father is supportive to the mother, yet inactive in terms of caregiving. His role does not begin to evolve until 1976. Similarly, the role of mother outside of parenting is absent until 1968. For these reasons, we chose not to incorporate the latter two themes until they began to evolve in the text. The five themes arose organically from our close reading of the volumes. In our 


\section{THE SPOCKIAN MOTHER}

subsequent analysis we also assess the changes in Spock's advice throughout the editions and evaluate the extent to which Hays" "intensive mothering model" is consonant with these evolving images. Finally, we examine the assumptions which undergird each theme for the purpose of charting the evolution of the Spockian Mother.

\section{The 1946 Spockian Mother: Mother as Middle Class and Child-Centered}

Of the five themes identified in this series, three primary themes resonate in the 1946 edition: "good" childrearing practices, appropriate sources of authority, and how mother feels. In the 1946 edition, an unassailable priority for the Spockian Mother is childrearing. Keeping a home, raising children, and pursuing activities such as "sweeping" and "washing dishes," are her primary duties (Spock, 1946, p. 249). However, she counters the scientific doctrine of the previous decades as espoused by Holt and Watson, which presented her as an instrument whose function was to ensure the development of her child. The 1946 Spockian Mother should trust her common sense in the care and feeding of her children. She is respectful of the doctor's authority, and listens closely to advice as it is doled out by both Spock and her child's physician. Every aspect of childcare, from infanthood through adolescence is in her domain. The 1946 Spockian Mother is entirely responsible for childcare; however, Spock encourages mothers to obtain assistance from neighbors, relatives or a paid nurse, pointing out, "if you try to do everything by yourself and get exhausted, you will have to get help" (p. 9). Mothers are urged, "don't be afraid to relax, to be agreeable" (p. 257). When discussing "Special Problems," Spock notes single mothers "may feel lonely or anxious or cross at times, and ... will sometimes take it out on the child. This is all natural and won't hurt him too much" (p. 491). Finally, Spock even echoes the Watsonian dictums regarding the danger of an overprotective mother, arguing, "a worrisome mother is completely wrapped up in her baby... [and] . . [f] ussy worrisome attention is bad at 


\section{THE SPOCKIAN MOTHER}

all ages" (p. 103). Eventually, however, he discards the extreme behaviorist pronouncements of his antecedents and assures mothers, “don't be afraid to kiss your baby...” (p. 103). The 1946 Spockian Mother desires the best possible childhood for her children and feels that she will and can do whatever is necessary to achieve that reality. Her social and emotional life centers on her husband and children. Childrearing is her responsibility and she does not want to disturb her husband with inconsequential details as concerns their welfare.

The overall maternal image emerging from Spock’s 1946 text primarily reinforces patriarchal views of parenting. Underlying ideologies are embedded in a vision of Mother as insecure, with low esteem, and in need of constant reassurance. Her knowledge about childrearing is not and should not be derived from research, but from intuition. Spock's text functions to fortify her self-knowledge by providing expert advice and, somewhat incongruously, sanctioning mother's intuition. He observes, "caring for children with only the help of a book is not satisfactory, but it is better than nothing" (p. 1) and he offers his most famous advice, "you know more than you think you do" (p. 3) in various guises throughout the text. The image of mothering emerges as one which is somewhat contradictory. The Spockian Mother acts on intuition and emotion, but distrusts herself; she assumes complete responsibility for child care, but is not really qualified to do so; ultimately, she needs guidance and reassurance in all her choices regardless of whether her counsel is her husband, her doctor or herself.

The 1946 Spockian Mother may be comforted by the denouncement of Watsonian ideology which demanded that women maintain both emotional and physical distance from their progeny. She is torn between her desire to do what is best for her child (e.g., give "him" independence) and wanting to overprotect "him." Unlike the Watsonian image of Mother, the Spockian Mother has reliable instincts; however, she also understands that doctors are the 


\section{THE SPOCKIAN MOTHER}

ultimate sanctioning agents for all important decisions. The 1946 Spockian Mother loves her baby and will do whatever is necessary to make "him" happy and keep "him" healthy, and she looks to the experts to accomplish these tasks. She is reassured by childrearing advice but may be intimidated by jargon or complicated explanations, hence Spock uses simplistic language and provides definitions when needed. For example, she does not understand words such as “dehydrated" which Spock defines for her as "dried out” (p. 25). The 1946 Spockian Mother is generally compliant when listening to "doctor's orders" because her common sense tells her that she should listen to her doctor; it is Spock who affirms that following her instincts and the advice of her doctor are mutually compatible goals. Most significantly, the Spockian Mother has "common sense," though perhaps not in excess since she must consult a 500 plus page book in order to rear her child.

The 1946 Spockian Mother inhabits a world in which prevailing ideologies of family include the unequivocal acceptance of her role as child-care provider and housewife. She is not viewed as having a role outside of parenting and she willingly and enthusiastically accepts her role as that of mother and wife. She has the requisite skills and competencies required for mothering and managing a family, yet she is burdened with worry, inexperience, and an often absent spouse who is busy supporting her middle-class lifestyle. If she adheres to the common sense advice presented by Spock, she will see that her innate skills and competencies serve her well in fulfilling her primary role in society. She may be a nervous, anxious, lonely and exhausted new mother, but she is able to fulfill her primary role in society if she follows the child-centered advice of Spock. The 1946 Spockian Mother is one who mirrors Hays' Intensive Mother: she is middle-class, child-centered, and consults expert guided opinions on childrearing. Overall, sources of authority include mother's intuition, the doctor, and of course, The Common 


\section{THE SPOCKIAN MOTHER}

Sense Book of Baby and Child Care. The father's role is limited to vague support of his wife and child, while the mother's role as parent is paramount and exclusive. And, although Spock includes women of diverse socio-economic statuses in his examples, the overall standard of white, middle-class and heterosexual remains normative. Moreover, the psychological and emotional state of the 1946 Spockian Mother emerges as fragile and is frequently referred to as “anxious," "nervous," "tense," "despairing," "easily discouraged," "emotional” and "worried" throughout the text. He offers support but his reassurance assumes the need for such encouragement in the first place.

In this initial inception of the text, Spock challenges the institution of motherhood by giving voice to mothers in the childrearing process. Concurrently, however, Spock reinforces patriarchal conceptions of motherhood by implying that childrearing is intuitive, and thus, should be natural to all mothers. That same intuition is undermined by the caveat that mothers are unsure about their intuition and must rely on the "real" childrearing experts-doctors. The primary structure of this initial text consists of advice to mothers and posits the mother's intuition and the medical profession as the two sources of authority in parenting. Roles of the father in relation to parenting as well as roles of women beyond motherhood are largely absent. The Spockian Mother is an intensive matriarch, whose domain is in the home and whose only other interests are largely diversionary. She is an exemplar of 1940's white, middle-class motherhood.

The next iteration of Spock's landmark text is ten years in the making and Spock suggests that the book has been extensively edited, noting: "If you are an old reader of this book, you'll see that a lot has been added and changed, especially about discipline, spoiling, and the parents' part" (p. 13). Responding to critiques of his first text as promoting an overly permissive 


\section{THE SPOCKIAN MOTHER}

approach to childrearing, Spock tries to modify his perspective through advocating increased discipline and consequences for poor behavior. But to what extent does the vision of motherhood change, if at all?

\section{The 1957 Spockian Mother: Mother as Well-informed but Insecure}

The 1957 version of the text remains largely consistent with the 1946 edition and features the themes of "good" childrearing practices, appropriate sources of authority, and how mother feels. The 1957 Spockian Mother is well-informed by books, doctors, experienced mothers, and family and friends. This emphasis in the text suggests that a "good" mother is one who seeks out other perspectives in childrearing, further indicating that the 1957 mother, similar to the 1946 mother, is child-centered and needs encouragement from Spock to draw on her maternal intuition as well as additional resources. In assessing the second edition of Spock's text, we argue that the Spockian Mother remains virtually unchanged. Thus, she is still an iteration of an intensive mother who is white, heterosexual, middle-class and primarily responsible for childcare.

Overall, the primary guideline for "good" childrearing practices in the 1957 edition was to affirm her maternal instincts through seeking advice from appropriate sources of authority, including family members and doctors. As in the 1946 edition, mothers' roles outside of parenting are largely absent. The role of father in relation to parenting is one that is present, in a supportive but passive role. The 1957 Spockian Mother adheres to Hays' view of women as primary caretakers, who rely on expert guidance, and see childcare as emotionally absorbing.

Although U.S. culture underwent many changes from 1946 to 1957, we encounter much more radical change in the tumultuous sixties. In the third edition, Spock continues to promote an empowering message that challenges earlier ideals about motherhood, suggesting mothers have a primary voice in shaping childrearing; however, her ability to define "good" mothering 


\section{THE SPOCKIAN MOTHER}

for herself, continues to be undermined by the Spockian Mother's feelings of insecurity and reliance on other experts in childrearing.

\section{The 1968 Spockian Mother: Mother as Conscientious Parent and Concerned Citizen}

The 1968 version is the first edition to showcase all five themes identified in this series. The 1968 version of the Spockian Mother's child-centered approach to childrearing appears to be an iteration of what was later termed the "Republican Mother," by Kerber (1976) where, in order for the Republic to succeed, mothers must be schooled in virtue so they can teach their children how to contribute properly as future citizens. The Republican Mother "attempted to integrate domesticity and politics" and "represented a stage in the process of women's political socialization" (Kerber, 1976, p. 203). Kerber argues that the ideology "masked political purpose by promise of domestic service" (p. 188). The 1968 Spockian Mother's role as primary caregiver includes informed and active citizenship, adding to her list of domestic responsibilities. Despite the expansion of her world from domestic to public, Spock reinforces patriarchal ideas about motherhood by maintaining that her primary responsibility is in childrearing, albeit involving higher stakes — raising responsible citizens. Women are entrusted with the responsibility of raising moral citizens who will shape and if needed, confront inequity in contemporary society.

In this third edition of the text, the Spockian Mother's role of raising moral members of a world community is a significant addition to her previous monolithic mothering role. One major revision in the 1968 version of the text is what Spock identifies as his "realization" of "what is making the parent's job most difficult today... [a] child-centered viewpoint” (p. xvi). In Spock's letter to the reader of this new edition, he suggests that parents are not adequately teaching children about "their place in the world and their obligation to it" (p. xvi). This appears to be a striking departure from the 1957 version marked by a new section in the front matter of the 1968 


\section{THE SPOCKIAN MOTHER}

book titled, "What are your aims in raising a child?" (p. 10). Whereas the 1957 edition utilizes the introductory pages of the text to emphasize major ideas such as "relations with Grandparents" and "help for the mother," the 1968 edition prioritizes larger questions such as why "we are disillusioned" (p. 13) and "why we need idealistic children" (p. 16). That these larger issues in parenting are positioned before the more practical issues listed first in earlier versions (e.g., callers and visitors; equipment and clothing) suggests that the Spockian Mother should expand her role beyond navigating the concerns of her child, to that of nurturing an informed and active citizenry.

In the third iteration of Spock's text, the Spockian Mother undergoes a number of modifications. In 1968, Spock challenges earlier ideals about mothering that limited her role to domestic duties such as entertaining guests and housework, to include larger social responsibilities. While the 1946 and 1957 versions of Spock's text seem to animate a childcentered approach to child-rearing where the mother sacrifices her own needs and desires for that of her child, Spock expands roles as well as responsibilities for the mother. In earlier versions, the Spockian Mother was preoccupied with anxiety about her parenting choices. This theme remains consistent as the 1968 Spockian Mother is fearful of failing at parenting. The source of authority in parenting continues to include mother's intuition only if appropriately bolstered by research from the medical community. And, finally, although the father's role in relation to parenting remains primarily supportive, the mother's role outside of parenting is expanded to include active social responsibility.

By 1976, the Vietnam era is passing and the contemporary Women's Movement is making its concerns known on a broader tableau. Although the late 1960s heralded a tumultuous time in U.S. history, it was not until the 1970s that the impact of feminism became substantial in 


\section{THE SPOCKIAN MOTHER}

mainstream culture. It was also during this period that the phrase "the personal is political" gained ascendency and thus the very personal process of bearing and raising children became a subject for public dialogue. It was in this turbulent social climate that Spock produced the fourth iteration of his text.

\section{The 1976 Spockian Mother: Mother as Modern-Traditional Caregiver}

Of the five themes identified in this series, all of them emerge in the 1976 edition. The Spockian Mother, emerging from the Women's Movement in the 1970s, is still primarily responsible for childrearing and housekeeping, but as evening approaches is entitled to "companionship in the work she has had to do alone all day" (Spock, 1976, p. 28). In the seventies text, mothers are again cautioned to include the doctor in most decision-making as illustrated on the first page of the book, identical to the three previous versions: "Bringing up your child won't be a complicated job if you take it easy, trust your instincts, and follow the directions that your doctor gives you" (p. 1). And similar to earlier editions, Spock still uses the term "worry" repeatedly and describing mothers frequently as "anxious" and "upset."

Most significant in the fourth edition of the book however, by the 1970s, Spock revises his view regarding women's reliance on their husbands, thus redefining the role of the father in relation to parenting in the process. For example, Spock (1976) observes, "When a father does his share as a matter of course when at home, it does much more than simply lighten his wife's load and give her companionship in the work that she has had to do alone all day" (p. 28). Spock argues that fathers have significant responsibilities in the rearing of their children and that both men and their progeny will benefit from the increased interaction which results from this shift in accountability. Previously, the Spockian Mother had accomplished her goals with only marginal assistance from her spouse, but in the 1970s Spock (1976) makes a bold concession: "that the 


\section{THE SPOCKIAN MOTHER}

father's responsibility is as great as the mother's" (p. xix). This shift lays the groundwork for an equal partnership in parenting, even if it is not fully realized in Spock's overall vision in the book. The Spockian Mother of the 1970s--a decade that heralds the emergence of second wave feminism in the United States and the significant amplification of women's presence in the workplace--perceives that she is not solely responsible for all childcare responsibilities and furthermore, has a right to expect participation from the father.

Though articulated in the opening pages of the text, however, equal partnership in parenting does not reverberate throughout the text. For example, previously labeled, “The Father as Companion" the section is updated to, "Parents as Companions," but despite this new label, the section contains the same content as in previous editions justifying that boys and girls need a "friendly father" even though, he is "apt to come home wanting most of all to slump down and read the paper" (p. 356). Additionally, many of the visual illustrations in the text confirm that the mother is still the primary caregiver even though, at least superficially, parents are described as partners in parenting. For example, an illustration in the section on managing young children depicts a mother wearing an apron while embracing her child. There are two illustrations that feature fathers, but only one portrays him as involved in a childrearing task. In this image, he is attempting to feed a young child who is sitting on a table; instead of facing his father who has a spoon out ready to feed the baby, the child is leaning over the edge of the table watching a puppy. The father's face shows confusion and apprehension. These images reinforce Spock's attempts to incorporate fathers as partners in childrearing, but suggest that mothers are still "primary" and fathers are still "supporting" and therefore struggle with basic tasks such as feeding the baby. 


\section{THE SPOCKIAN MOTHER}

While the Spockian Mother is portrayed as generally middle-class, there is some consideration in this edition that she may not always have substantial resources to live out the American dream of middle-class parenting. For example, when advising parents about the importance of children sleeping alone rather than in a family bed, Spock acknowledges by implication that some parents may need to keep children in the parents' room due to financial constraints. He recommends with qualifications, "If it is possible, it's fine for children to have a room of their own..." (Spock, 1976, p. 201). The Spockian Mother indicates awareness of those whose financial circumstances are more marginal, but still appears to wear the guise of the comfortable middle class world in which her predecessor resided.

The 1976 edition of Spock's book appears in bookstores after the anti-war movement is fading and hippies are being relegated to historical accounts of the 1960's. Additionally, women are moving into the workforce in ever-greater numbers and the image of the Spockian Mother is challenged by feminists who accuse Spock of nothing short of misogyny. So what does the seventies version of the Spockian Mother look like, as she adapts to this brave new world? The Spockian Mother of the seventies is not as singularly focused on the role of caregiver as were her forbearers. She may have employment outside the home, regularly seek consultation from friends and family, and may even demand participation in parenting activities from her husband. The 1976 Spockian Mother, albeit a better-educated and possibly "working" mother, is still not especially intellectual. Young and new mothers still emerge as "stay-at-home moms," but mention of working mothers is underscored with increasing frequency. In the fourth edition of Spock's text, the Spockian Mother's singular responsibility in the home is challenged for the first time. Spock interrogates the earlier assumptions in previous editions that mothers are the primary caregivers of children. Fathers are given more attention than in previous editions and women's 


\section{THE SPOCKIAN MOTHER}

work outside of childcare is acknowledged. Overall, however, Spock continues to reinforce the traditional view that mothers are the primary caregivers of children while doctors should be included prominently in childrearing decision-making. The enduring guideline for "good" childrearing practices, as well as the continuing appropriate source of authority, remains the same as the patriarchal standard: mothers should trust the experts. Additionally, fathers are elevated as appropriate sources of authority in parenting advice, alongside of mothers. Finally, the role of the mother outside of parenting is multidimensional. Earlier assertions that mother needs to expand her role to that of active citizen have been supplemented to acknowledge the potential for an additional role as a mother who works outside of the home.

Almost a decade later, in 1985, Spock collaborates with pediatrician, Michael B. Rothenberg to move his text into an even more contemporary position in the burgeoning childcare marketplace. In this edition, the co-authors indicate that "[m]ore space has been given to the problems of divorce, single-parent families, and the difficulties of the stepparent relationship" (Spock \& Rothenberg, 1985, p. xii). The text features additional material primarily focused on issues that relate to the increase of mothers in the workplace. This edition offers more agency to readers as Spock cautions parents to "not take too literally what is said in this book" and to remember that "you know a lot about your child and I don't know anything" (p. xv). Mothers are given "permission" to challenge traditional norms of mothering by calling on personal expertise that may be outside of patriarchal conceptions of motherhood. Spock's collaboration with a younger co-author helped move the book further along in its efforts to mirror the changing landscape of gender relations in the public and private spheres.

\section{The 1985 Spockian Mother: Mother as Multifaceted Modern Co-Parent}




\section{THE SPOCKIAN MOTHER}

Similar to the 1976 edition, each of the five themes in the Dr. Spock series are manifest in the 1985 version. One of the supplements to this edition is a section on breastfeeding for the working mother. Spock begins the section by asking, "What about the woman who hesitates to nurse because she has to go back to work?" (p. 95). The answer suggested is that it "depends on her working hours and how soon she must get back to the job" (p. 95). This framing suggests that the mother is the primary source of authority in parenting, and that she feels she is primarily responsible in making this decision. In the 1985 edition, Spock and Rothenberg elaborate on the introductory paragraph by explaining that "she needs to decide," encouraging her to "talk to some mothers who have nursed after going back to work, before you have your baby" (p. 96). The advice offered by experienced mothers is detailed and specific, consisting of seven suggestions that include, "try to nurse right before and right after work and to express your milk at least once if you're working longer than 6 hours" (p. 96). Following the recommendation to talk to experienced mothers, the authors reassure the new mother that, "of course, you'll find what works best for you and your baby within a few weeks" (p. 97). There is an implicit message that the Spockian Mother will gather information and make a choice that is appropriate for her and for her child. This message assumes a stereotypical, western male ideological perspective that all problems are solvable if we simply work hard enough to uncover the "right" answer. Conversely, from this perspective, if the new mother does not find what works "best for her" and her child, and if her family members suffer as a result, she has failed in this most important task.

The role of the father in relation to parenting is expanded in the 1985 edition and is featured in a section on the supportive father in pregnancy and delivery. For example, in section 37 fathers are authorized to, "be an integral and essential part of the pregnancy and labor" (p. 30). His role has changed from that of being absent to being a supportive parent and Spock and 


\section{THE SPOCKIAN MOTHER}

Rothenberg (1985) observe a multitude of ways in which the father can participate in pregnancy and childbirth:

He may go to prenatal doctor visits and attend childbirth classes with his wife. He may be an active participant in the labor and in some hospitals may 'catch' the infant as it is born, cut the cord or carry the child to the nursery, watching over him while the mother is being cared for in the delivery room. He may have unlimited access to mother and infant during hospitalization. If the mother is unwell or if the baby has special problems, he may be the parent most actively involved with the baby in the early hours after the baby's birth. He no longer has to be the lonely, disgruntled onlooker. (p. 30)

This new section reveals that the father has liberty in choosing how to be active with the mother in his caregiving role, even achieving a primary role if the mother is unable to fulfill her duties. While there is some modification of the father illustrated in earlier editions who fulfills much of his paternal duty when he drops his wife at the hospital, he still plays a supporting role rather than one in which he is an equal partner in parenting.

The 1970s theme of expanding roles for mothers outside of parenting, continues with mothers as multifaceted parents and active citizens in the 1980 s version of the text. Toward that end, Spock's introduction to the new edition addresses "children's fear of nuclear war" (p. xii), calling for active parents to demonstrate by example that they support significant global issues such as working toward world peace. Spock suggests that parents can assuage their child's fears by seeing their active participation in the political process.

In the fifth edition, Spock continues to emphasize parenting as an equal partnership, especially in response to cultural changes in the 1980s - specifically, the increase of mothers in the workplace. Despite the accommodations to this cultural change, Spock undermines the equal 


\section{THE SPOCKIAN MOTHER}

parenting partnership theme and continues to reinforce traditional patriarchal views by predominantly asserting that mothers are primarily responsible for childrearing decisions.

Overall, parental advice to women is to retain their roles as primary caregivers, rely on their instincts, and continue to consult the medical profession for all major decisions. However, the role of the father in relation to parenting continues be elevated toward equal partnership, albeit fleetingly. The role for women outside of motherhood persists as that of concerned citizen, and grows progressively more active in the work world as well. However, despite her added responsibilities, the Spockian Mother is ultimately a traditional mother, embodying Hays' model of intensive mothering as primary caretaker.

Along with Rothenberg, Spock published a final iteration of his international best-seller in 1992, in which the Spockian Mother ventures further into the public sphere through work outside the home and into the political arena. But a particular shift in her disposition also brings her almost full-circle to the old stereotype of woman as moral guardian of the family. In this edition, the struggle persists between reinforcing patriarchal views of parenting and challenging those traditional views. Spock and Rothenberg recreate the Spockian Mother as the woman who emerges from the 1980's ready to "have" and therefore "do," "it all."

\section{The 1992 Spockian Mother: Mother as Emotional, Social, and Intellectual Compass}

In the final iteration of the Dr. Spock series, all five themes again emerge from the text. In 1992, the Spockian Mother grows more dependent on the physician, and is admonished, "the doctor knows your child, and is the only person in a position to advise you wisely" (Spock \& Rothenberg, 1992, p. xiii). This emphasis illustrates his conviction that although women's roles were changing in the workplace and in the home, the medical community remained the central authority on childcare. 


\section{THE SPOCKIAN MOTHER}

By 1992, Spock makes a number of concessions to the diversity of family situations which compose American culture, noting the "new material and emphases [contained] in the current edition" (Spock \& Rothenberg, 1992, p. xvi) including divorce, single-parent families, stepfamilies, breastfeeding, working mothers and adoption. It is difficult to assess how much the change was prompted by the publishers, the changing culture, or by Spock and Rothenberg themselves, but the content clearly incorporates a more diverse view of "family" from that in previous editions.

Although the Spockian Mother as anxious specter remains a pervasive theme throughout each edition, she appears somewhat more composed by 1992. For example, there is a marked decrease in portrayals of mothers as feeling worried, anxious and upset, relegating this depiction primarily to "first-time" and "new moms." "Anxious," "uneasiness," "fret," and "worry," appear repetitively through 1985 and are subsequently replaced in the 1992 text with more precise reassurances such as “it's probably instinctive for parents to be overly protective at this period [first few weeks]" (p. 7) and "[t]he uneasy feeling you have when you hear her cry, the feeling that you want to comfort her, is meant to be part of your nature, too" (p. 11). While Spock and Rothenberg (1992) note that "most mothers are also anxious about assuming the care of their first baby in the beginning" (pp. 27-28, emphasis added), they are careful to distinguish between firsttime mothers and those who have more experience. Veteran mothers are depicted as feeling more confident, presumably based on their maternal experience with earlier offspring. He points out, for example, that "the more experienced parent isn't afraid to be friendly and reasonable" (Spock \& Rothenberg, 1992, p. 455). The shift in emphasis is almost imperceptible as indicated through the substitution of "most" with "new" or "first-time" throughout the edition. 


\section{THE SPOCKIAN MOTHER}

In the 1990s, Spock's guidance is still straddling the dual path of science versus intuition, but he also acknowledges the societal changes that influence women's roles, noting, for example, that parenting "is greatly complicated in the twentieth century by the fact that parents have all read psychology of one kind or another and have been made uneasy about the theoretical possibility of doing harm by well-intentioned efforts" (Spock \& Rothenberg, 1992, p. 470). This more contemporary Spockian Mother is portrayed as better read than her predecessor but the ironic consequence of her increased education is to further weaken her already tenuous selfesteem. For example, Spock argues that this subsequent unease is "too bad...because in most cases it's better to do the supposedly wrong thing with an air of confidence than the supposedly right thing with a hesitant or apologetic manner" (Spock \& Rothenberg, 1992, p. 570). It might appear that the Spockian Mother was at an advantage acting on instinct rather than trying to utilize new approaches to childrearing that she might not accomplish with reasonable selfpossession.

Through the previous five editions, the Spockian Mother gains in education, intellect and worldliness and expands her purview to the world of work, politics and other interests not directly interwoven with childrearing. Her function as the emotional, social, and intellectual compass, becomes the three pillars that build the "foundation on which the child's future relationships with all the other people in her life will be built" (p. 46). Childrearing remains her primary concern, though it is balanced with a much broader spectrum of activities than those of her early counterparts. Even in the 1990s, when her male complement becomes less of a "companion" and more of a "partner" she is still clearly in charge of the entire operation of childrearing. And, although appropriate sources for authority include the mother, dominion remains with that of the physician. Finally, in the 1992 edition of Spock's book, the Spockian 


\section{THE SPOCKIAN MOTHER}

Mother continues to align with the patriarchal intensive mothering model that Hays' suggests undermines personal choice in selecting mothering options.

\section{Implications}

Throughout the decades, Spock's text has had immeasurable impact on our cultural views of motherhood, fatherhood and childrearing. The rhetorical specter of the Spockian Mother thrived in the roles of Mother and Wife, as defined and dictated by a postwar mentality with clearly defined roles for women and men in American culture. As well-intentioned as Spock may have been in his aspiration to undo the harms of his forerunners by challenging patriarchal views of childrearing, he also reified the vision of Mother as frail, weak, and in need of guidance from the patriarchal structure which evaluates and judges her successes and failures in what is deemed her most important social role. In respect to his childcare advice, Spock has been accorded accolades from contemporary critics such as, "maybe Dr. Spock was right after all” (Shea, 2003, p. 2), but for many women, Spock's message also affirmed and, to some extent, actually created restricted roles for mothers.

In the hundred or so years which preceded the publication of Spock's text, the image of Mother had taken such a battering in the fields of science and medicine, women were eager to embrace Spock's “kinder, gentler” conception of Mother. However, this new image still trapped women in the confines of a rigid and stereotypical view of their gender that was consistent with Spock's view of women's roles prior to the Women's Liberation Movement. ${ }^{v}$ Consequently, while Spock's text most likely produced a more positive outcome for generations of children growing up in the 1940s and 1950s, Spock's hegemonic discourse generated new layers of oppression for the women he presumed to support. 


\section{THE SPOCKIAN MOTHER}

As proponents of second wave feminism took aim at The Common Sense Book of Baby and Child Care, Spock expressed dismay to discover that his book was touted as what Gloria Steinem called a "symbol of male oppression" (Maier, 1998, p. 353). According to Spock, "Before 1970, a lot of women had implied that, in one way or another by buying my book, that I was a friend to mothers. It was quite a shock to me to be told by some of the 1970 s feminists that I was an enemy of women" (Maier, 1998, p. 354). It may be unrealistic to expect that Spock's work could or should have challenged the patriarchal culture from which he emerged and equally impracticable for him to be conscious of the damage his parenting advice would do to women's agency. But in adhering to patriarchal norms of motherhood, the current analysis indicates that his construction of the Spockian Mother reified the dominant discourse relegating women to roles as caretakers of children. The standard for "good" mothering in the Spock texts, evolved out of the historical circumstances of the times yet in his effort to expand women's roles from primary caregiver to childrearing partner, Spock encouraged mothers to strive for a standard that was likely unattainable for many if not most — a child-focused ideology that encompassed both domestic responsibilities and obligations to the larger society.

The image of the Spockian Mother gradually shifted from a construction that served to maintain oppression in the 1940 s-1960s, toward one that reluctantly offered a "challenge" and "resistance" to such oppression in its construction of gender through the 1970s-1990s. While the Spockian Mother appears to have undergone significant transformation she concomitantly remained a construct that is still the creation of a patriarchal vision of women and motherhood. She grows into a more autonomous being with increased options and support, but can only occupy as much space as that which is allotted to her by phallocentric institutions that are invested in selling disposable diapers, baby bottles, and self-help books to a never-ending 


\section{THE SPOCKIAN MOTHER}

population of new mothers. What is especially revealing in subsequent revisions of the text is that while the baby as "generic he" has been replaced with alternating gender pronouns, the audience for each incarnation is still "Mother"; presumably "Father" only reads what his spouse or partner shares with him and only then if he has time amidst his other responsibilities.

Who was the Spockian Mother of the twentieth century? The constructions of the Spockian Mother vacillated between reinforcing patriarchal views and challenging traditional views of motherhood. The 1946 and 1957 Spockian Mother is moral and upright, but anxious and consumed with childrearing. The 1968 and the 1976 Spockian Mother continues to be virtuous and also must apply that quality to her larger civic duty. The 1985 and 1992 Spockian Mother has increased responsibilities due to her active role in the public sphere. She is the precursor to the twenty-first century Mother who continues the struggle with self-definition, wresting her from the vestiges of a vision that can never be fully realized and which was never designed to allow autonomy and agency in selecting mothering options despite the enduring mantra to "trust" herself. By tracing the evolution of the Spockian Mother through decades of cultural advancement, our analysis reveals that the institution of motherhood restricts personal agency within the patriarchal structure in which she is produced. Certainly, contemporary women are not required to subscribe to mothering doctrines as they are articulated through popular culture and media, however, a lack of alternative mainstream perspectives may limit women's capacity in creating a more empowered mothering role. Feminist theory might allow us to posit that women have a significant responsibility in either accepting or challenging ideas which restrict agency, but for many women the challenge of balancing work outside the home with parenting practice, does not allow the luxury of developing unconventional parenting choices. The inheritance of patriarchal institutions in western culture continues to shape much of 


\section{THE SPOCKIAN MOTHER}

our perception of what is and is not normal and normative, and our ability to defy those conventions in the last century or so has been truly spectacular in the history of western civilization. Given that mothering is a primary way we produce and reproduce culture, understanding mothering options--and ultimately, parenting options--is vital to our feminist evolution. In regard to this specific project, while Spock is no longer generating the images that influence the Spockian Mother, his enduring legacy still underlies the enormous undertaking that is childrearing as defined in contemporary culture.

\footnotetext{
${ }^{\mathrm{i}}$ The Common Sense Book of Baby and Child Care sold more than 750,000 copies in its first year (Maier, 1998) and was subsequently revised six times during Spock's lifetime, as well as since his death in 1998, as recently as 2012.

ii Although Spock's book continued to be revised after his death in 1998, we have limited the scope of our analysis to those texts published in his lifetime since they represent Spock's vision of the Spockian Mother.
}
iii Although both Jane and Benjamin Spock worked on the manuscript, Benjamin Spock is listed as the sole author. It is not until 1976 that Spock officially acknowledged the extent of his wife's contributions to the book.

iv Spock elects to use the generic "he" when referring to the baby throughout the 1946 text. He explains his choice in the forward of the book, "I want to apologize to half the fathers and mothers who are going to read the book. I mean the parents whose first baby is a girl. Everywhere I've called the baby 'him.' I think girl babies are as wonderful as boy babies. But in every sentence I can't say 'her or him' and I can't say 'it' (parents would rather have their baby called by the wrong sex than be called 'it'). Why can't I call the baby 'her' in at least half of the book? I need 'her' to refer to the mother. I hope the parents of girls will understand and forgive me" (p. 2).

v See for instance, Spock, B. (1969). Decent and indecent: Our personal and political behavior, and Spock, B. (1974). Raising children in a difficult time. 


\section{References}

Bloom, L. Z. (1972). Doctor Spock. Indianapolis, IN: The Bobs Merrill Company Inc.

Buchanan, L. (2013). Rhetorics of motherhood. Carbondale and Edwardsville: Southern Illinois University Press.

Douglas S. J., \& Michaels, M. W. (2005). The mommy myth: The idealization of motherhood and how it has undermined women. New York: Free Press.

Dubriwny, T. N., \& Ramadurai, V. (2013). Framing birth: Postfeminism in the delivery room. Women's Studies in Communication, 36(3), 243-266.

Enoch, J. (2012). There's no place like the childcare center: A feminist analysis of $<$ home $>$ in the World War II era. Rhetoric Review, 31(4), 422-442.

Foss, S. (1996). Rhetorical criticism: Exploration and practices (2 ${ }^{\text {nd }}$. ed.). Prospect Heights, IL: Waveland Press Inc.

Foss, S. (2009). Rhetorical criticism: Exploration and practice. (4 ${ }^{\text {th }}$ ed.). Long Grove, IL: Waveland Press, Inc.

Foss, K. A., \& Domenici, K. L. (2001). Haunting Argentina: Synecdoche in the protests of the mothers of the Plaza de Mayo. Quarterly Journal of Speech, 87(3), 237-258.

Gilbert, J. (2008). Why I feel guilty all the time: Performing academic motherhood. Women's Studies in Communication, 31(2), 203-208.

Harris, L. (2002). The court, child custody, and social change: The rhetorical role of precedent in a 19th century child custody decision. Rhetoric Society Quarterly, 34(1), 29-46.

Hays, S. (1996). The cultural contradictions of motherhood. New Haven, CT: Yale University Press. 
Hidalgo, L. (2011). Dr. Spock's Baby and Child Care at 65. BBC. Retrieved from http://www.bbc.com/news/world-us-canada-14534094

Holt, L. E. (1894). The care and feeding of children: A catechism for the use of mothers and children's nurses. New York, NY: D. Appleton and Company.

Kaye, J. (1993). The life of Benjamin Spock. New York, NY: Twenty-First Century Books.

Kerber, L. (1976). The republican mother: Women and the enlightenment-An American perspective. American Quarterly, 28(2), 187-205.

Maier, T. (1998). Dr. Spock: An American life. New York, NY: Harcourt Brace \& Company.

Margolis, M. (2000). True to her nature: Changing advice to American women. Prospect Heights, IL: Waveland Press.

Meakin, J., \& Tattersall, K. (2004). Biographical perspectives. Visions. Retrieved 8/31/2004 from www.vision.org/jrnl/0006/bvbspock.html.

O’Brien Hallstein, D. L. (2006). Conceiving intensive mothering. Journal of the Association for Research on Mothering, 8(1-2), 96-108.

O’Brien Hallstein, D. L. (2010). White feminists and contemporary maternity: Purging matrophobia. Basingstoke, Hampshire, GBR: Palgrave Macmillan. Retrieved from http://www.ebrary.com

O'Reilly, A. (2006). Between the baby and the bathwater: Some thoughts on a mother-centered theory and practice of feminist mothering. Journal of the Association for Research on Mothering, 8(1-2), 323-330.

Rich, A. (1986). Of woman born: Motherhood as experience and institution. New York and London: W. W. Norton \& Company. 
Shea, R. H. (2003). Baby steps. U.S. News and World Report, 134(17), p. 44, 2p. Retrieved from http://web25.epnet.com.

Spock, B. (1946). The common sense book of baby and child care. New York, NY: Duell, Sloan and Pearce.

Spock, B. (1957). The common sense book of baby and child care. New York, NY: Pocket Books.

Spock, B. (1968). Baby and child care. New York, NY: Pocket Books.

Spock, B. (1969). Decent and indecent: Our personal and political behavior. New York, NY: The McCall Publishing Company.

Spock, B. (1974). Raising children in a difficult time. New York, NY: W.W. Norton and Company, Inc.

Spock, B. (1976). Baby and child care. New York, NY: Pocket Books.

Spock, B., \& Rothenberg, M. (1985). Baby and child care. New York, NY: Pocket Books.

Spock, B., \& Rothenberg, M. (1992). Dr. Spock's baby and child care. NY: Pocket Books.

Watson, J. (1928). Psychological care of infant and child. New York, NY: W.W. Norton and Company, Inc. 